\title{
Relationships between body composition and anaerobic performance parameters in female handball players
}

\author{
Mehmet Kale ${ }^{\mathrm{ABCDE}}$, Erkan Akdoğan ${ }^{\mathrm{BDE}}$ \\ Eskişehir Technical University, Eskişehir, Turkey
}

Authors' Contribution: A - Study design; B - Data collection; C - Statistical analysis; D - Manuscript Preparation; E - Funds Collection.

\begin{abstract}
Purpose:

The purpose of this study was to investigate of the relationships between total/segmental body composition and anaerobic performance parameters in female handball players.

Material: Voluntary 16 women handball players (age $=19.6 \pm 2.6 y e a r s$, body height $=168.0 \pm 5.5 \mathrm{~cm}$, body weight $=$ $64.7 \pm 10.7 \mathrm{~kg}$ ), trained last 3 years, were participated to the study. Twelve of them were students from Faculty of Sports Sciences. All measurement and tests were completed in the week right after Turkish Women Handball 1th League. Total and segmental body composition parameters (body fat percentage, body fat mass, lean body mass, leg fat percentage, leg fat mass, lean leg mass, torso fat percentage, torso fat mass, and lean torso mass) of each player were evaluated with dual-energy X-ray absorptiometry method. Squat jump test for explosive power, countermovement jump test for elastic (reactive) power, and Wingate test for anaerobic power (WAnT AP) and anaerobic capacity (WAnT AC) were used. Relationships of total/segmental body composition parameters with jump and anaerobic power-capacity parameters were analysed with Pearson correlation and the probability level was set to $\mathrm{p} \leq 0.05$.

Results: $\quad$ As a result of statistical analyses, there were negative relationships $(p<0.05)$ between anaerobic performance parameters (countermovement jump and anaerobic power-capacity) and total/segmental body composition parameters except for lean body mass, lean leg mass, and lean torso mass.

Conclusions: Total/segmental body composition parameters based on endomorphy had negative effects on explosive power, elastic power, WAnT AP and WAnT AC. It is suggested that coaches should not allow female handball players to rise in ectomorphy for the anaerobic performance loss in the season finale.

Keywords: handball, segmental body composition, squat jump, counter movement jump, anaerobic power-capacity
\end{abstract}

\section{Introduction}

Body composition analysis is one of the common evaluation methods in professional sport, allowing changes in anthropometric and physiological status to be monitored [1]. Accordingly, an accurate body composition assessment is necessary for coaches, strength and conditioning specialists and athletes. Body composition is well known to be relevant to performance in with special attention being paid to the total and regional fat and lean mass proportions. Over the last several years, dual-energy X-ray absorptiometry (DEXA) has become the gold standard for body composition analysis, allowing reproducible estimates of total and segmental body composition parameters (body fat percentage, body fat mass, lean body mass, leg fat percentage, leg fat mass, lean leg mass, torso fat percentage, torso fat mass, and lean torso mass) [2].

Team handball is an intermittent team sport, characterized by high-intensity explosive movements such as sprints, jumps, throws and physical confrontations, which are interspersed with periods of low-intensity activities such as standing, walking and jogging [3]. Success in team handball is determined by a variety of technical and tactical, mental, anthropometric and physical performance characteristics [3, 4]. Several studies have reported that, in handball players, in addition

\footnotetext{
(c) Mehmet Kale, Erkan Akdoğan, 2020

doi:10.15561/20755279.2020.0502
}

to the technical skills and tactics, the anthropometric characteristics, and highs levels of force, and power constitute the determining factors for the competitive success $[4,5]$. Testing and evaluating for performance are the main subjects of sports sciences studies because they play key roles in training and competition [6]. Sportive performance is influenced by the sex and age of the players but, relative to those of male players, there are few studies of female players.

Sportive conditioning is usually divided into 3 training phases (pre-season, in-season, and post-season). Pre-season training aims at maximizing the physical and fitness parameters before the start of the competitive season; in-season, the goal is to maintain the physical and fitness levels achieved during the pre-season. It may be suggested that physical status should peak by the end of the pre-season phase and be maintained throughout the entire competition period [7].

Information on the variations in anthropometry of handball players over the competitive season is quite limited. Monitoring the body composition of handball players throughout a competition cycle could provide valuable information to create an anthropometric profile of each individual player. This can also help prevent changes in body composition that may be detrimental to performance, and provide reference body composition values that can be targeted after a period of detraining 
or injury, and act as an indicator of physiological status and training. Actually, the role of body composition in functional performance of association male handball players has been extensively investigated. However, to our knowledge, very few studies has analysed the relationships between anaerobic power-capacity and jump ability with body composition in female handball players. The purpose of this study was to investigate the relationship between total/segmental body composition and anaerobic performance parameters in female handball players.

\section{Material and Methods}

\section{Participants}

Volunteered 16 female handball players $(\mathrm{age}=$ $19.6 \pm 2.6$ years, body height $=168.0 \pm 5.5 \mathrm{~cm}$, body weight $=$ $64.7 \pm 10.7 \mathrm{~kg}$ ) from the Super League Team participated in this study. Twelve of them were students from Faculty of Sports Sciences. All participants performed regular handball training at least six times a week (including a competitive game once a week) and strength/power training at least three times a week for a minimal period of 5 -years. All procedures of the study were explained to the subjects. A written informed consent was obtained from each participant to participate in the study in accordance with the ethical standards of the Helsinki Declaration. The study was approved by the Clinical Research Ethics Boards of Osmangazi University. Participants were told not to take any drugs, coffee or alcohol and not to be physically active at least $24 \mathrm{hr}$ before test day.

\section{Procedures}

All measurement and tests were completed in the week right after Turkish Women Handball 1st League after the laboratory visit for $120 \mathrm{~min}$ of total tests at a specific time (09:00-11:00) of days on three occasions to complete familiarization and main trials. Subjects were measured with dual-energy X-ray absorptiometry method for total and segmental body composition parameters (body fat percentage, body fat mass, lean body mass, leg fat percentage, leg fat mass, lean leg mass, torso fat percentage, torso fat mass, and lean torso mass). They took part in squat jump test (SJ) for explosive power, countermovement jump test (CMJ) for elastic (reactive) power, and Wingate anaerobic test (WAnT) for anaerobic power (WAnT AP) and anaerobic capacity (WAnT AC).

Anthropometric Characteristics

Body weight was measured to nearest $+0.1 \mathrm{~kg}$ with a scale (SECA, Hamburg). Body height was measured to the nearest $+0.1 \mathrm{~cm}$ between head's vertex point and foot using a wall mounted stadiometer (Holtain Ltd, UK) after a deep inspiration. Each subject was only her athletic body suit and barefoot. Whole body and regional composition (body fat percentage, body fat mass, lean body mass, leg fat percentage, leg fat mass, lean leg mass, torso fat percentage, torso fat mass, and lean torso mass) was evaluated by means of DEXA using a total body scanner the Dual-energy X-ray absorptiometry (Lunar Prodigy Pro; GE, Healthcare, Madison, WI, USA) according to the manufacturer's procedures. The scanner calibration was completed using phantoms as per manufacturer's standard directions in the morning before the measurements. All scanning and analyses were performed by the same operator to ensure consistency. Prior to the assessment all subjects were advised not to wear any jewellery or to have any metal on their bodies during the scanning process. In order to ensure a standard supine position was adopted during the scans, the subjects' knees and ankles were tied with a Velcro strap while their arms were extended by their sides. Typical duration of the examinations was from 6 to $8 \mathrm{~min}$, depending on the height of the subject.

\section{Wingate Anaerobic Test (WAnT)}

The WAnT (Monark Exercise AB, Sweden) was performed on a cycle ergometer (894 Ea Peak Bike, Monark Exercise AB, Sweden), for 30 s, at an "all out" pace. The ergometer was calibrated, and seated height was adjusted for each subject's leg length. Each subject pedalled up to his maximum rpm level at least 3 times during the $5 \mathrm{~min}$ warm-up period (at 60-70 rpm) and then a 5-min recovery was followed. The researcher placed the appropriate amount of weight (between $1 \mathrm{~kg}$ and 100 gr) on the weight carriage. Subjects were instructed to begin pedalling with all resistance of the flywheel until they reached their maximum rpm within $4 \mathrm{~s}$. At this point, immediately the predetermined fixed resistance $(75 \mathrm{gr}$ per kg of body weight) was released to the flywheel and remained there till the end of the test [8]. Players were motivated in all test period. WAnT AP was the highest power output in $5 \mathrm{~s}$ interval of the test. WAnT AC was the mean power output in $30 \mathrm{~s}$ test. WAnT AP and WAnT AC were expressed as W. $\mathrm{kg}^{-1}$ for statistical analysis.

\section{Vertical Jump Measurements}

The subjects performed SJ and CMJ tests using by a jump test device (Smartjump, Fusion Sport Pty Queensland, Australia) as described Kale et al. (9). Each subject had a 15-min warm-up including self-paced running, calisthenics and flexibility exercises before the tests. Subjects flexed the knees for SJ until a comfortable starting position, semi-squatting position occurred normally at a knee angle of about 85 degrees [10] without a preliminary downward movement. Each subject maintained his posture at least 2 seconds, which prevented the pre-stretching of muscles from any preliminary downward movement before SJ. CMJ was started from an upright standing position following a preliminary downward movement by flexing the knee approximately to the same knee angle as SJ starting position. Each subject performed 2 attempts for each jump test from the starting position and landed on switching mat with the legs kept straight and hands kept on the hips to provide standardization. One-minute rest period was given after each attempt. To prevent possible positional differences in each vertical jump test, the subjects were instructed to take off from and land on the switching mat in the same position and place. The best attempt expressed in $\mathrm{cm}$ for each jump test was used for the statistical analysis.

Statistical Analyses

SPSS 18 software (SPSS Inc., Chicago, IL, USA) 
was used to analyse statistically the data. Shapiro-Wilk normality test was used to test of normality. All variables were distributed normally $(\mathrm{p}>0.05)$. Data are presented as mean and standard deviation (mean $\pm \mathrm{SD}$ ). Relationships of total/segmental body composition parameters with jump and anaerobic power-capacity parameters were analysed with Pearson correlation analyses. Statistical significance was set to a probability level of $\mathrm{p} \leq 0.05$.

\section{Results}

The descriptive statistics of physical and body composition parameters are presented in Table 1. The results of anaerobic performance tests are also presented in Table 2. Additionally, the correlation coefficients among the measured parameters are shown in Table 3. As a result of statistical analyses, CMJ and WAnT AC had only negative relationships $(\mathrm{p}<0.05)$ with body fat percentages, body fat mass, leg fat percentages, leg fat, torso fat mass, lean torso mass except for lean body mass, lean leg mass, lean torso mass. SJ and WAnT AP had no significant correlations with total/segmental body composition parameters.

Table 1. The descriptive statistics of physical and total/ segmental body composition parameters $(n=16)$. Data are reported as mean $\pm \mathrm{SD}$.

\begin{tabular}{ll}
\hline Parameters & Mean \pm SD \\
\hline Age (years) & $19.6 \pm 2.6$ \\
Body height $(\mathrm{cm})$ & $168.0 \pm 10.7$ \\
Body weight $(\mathrm{kg})$ & $64.7 \pm 5.5$ \\
Body fat percentage $(\%)$ & $32.3 \pm 4.9$ \\
Body fat mass $(\mathrm{kg})$ & $20.0 \pm 6.6$ \\
Lean body mass $(\mathrm{kg})$ & $40.6 \pm 4.5$ \\
Leg fat percentage $(\%)$ & $3.6 \pm 0.4$ \\
Leg fat mass $(\mathrm{kg})$ & $8.6 \pm 2.5$ \\
Lean leg mass $(\mathrm{kg})$ & $14.8 \pm 1.9$ \\
Torso fat percentage $(\%)$ & $29.6 \pm 5.7$ \\
Torso fat mass $(\mathrm{kg})$ & $8.9 \pm 3.4$ \\
Lean torso mass $(\mathrm{kg})$ & $20.3 \pm 2.1$ \\
\hline
\end{tabular}

Table 2. The results of anaerobic performance tests ( $n=$ 16). Data are reported as mean $\pm S D$.

\begin{tabular}{ll}
\hline Parameters & Mean \pm SD \\
\hline SJ $(\mathrm{cm})$ & $22.9 \pm 3.82$ \\
CMJ $(\mathrm{cm})$ & $24.4 \pm 3.69$ \\
WAnT AP $($ Watt.kg-1) & $6.80 \pm 1.02$ \\
WAnT AC $\left(\right.$ Watt.kg $\left.{ }^{-1}\right)$ & $5.25 \pm 1.29$ \\
\hline
\end{tabular}

Notes: SJ= Squat Jump; $\mathrm{CMJ}=$ Countermovement Jump; WAnT $A P=$ Wingate Anaerobic Test Anaerobic Power; WAnT AC = Wingate Anaerobic Test Anaerobic Capacity.

\section{Discussion}

The primary result of the present study demonstrated that the end of the season led to significant negative body composition relationships with CMJ and WAnT AC. Additionally total/segmental body composition parameters had no significant relationship with SJ and WAnT AP. Due to the increase in the body fat of female handball players, this study result indicated that some performance parameters decreased at the end of the season.

There were some studies on monitoring the anthropometry and body composition of female handball players throughout the in-season. Granados et al. [11] were studied to examine the effects of an entire season on anthropometric characteristics in 16-elite first league Spanish female handball players. The results showed that, over the season, significant increases were occurred in fat-free mass $(1.8 \pm 1.2 \%)$ and a significant decrease in body fat percentage $(9.0 \pm 8.7 \%)$. Similar to this study, Milanese et al. [7] reported that the total body mass and lean body mass were unchanged. However, they stated that body fat mass and body fat mass percentage were slightly decreased $(-2.24 \%$ and $0.40 \%$, respectively) over the competitive phase in forty-three Caucasian female handball players. It indicates that female handball players who developed larger decreases in body fat percentage, showed larger decreases in maximal strength or muscle

Table 3. Relationships between total/segmental body composition and anaerobic performance parameters on female handball players

\begin{tabular}{|c|c|c|c|c|c|c|c|c|}
\hline \multirow{3}{*}{$\begin{array}{l}\text { Body Composition } \\
\text { Parameters }\end{array}$} & \multicolumn{8}{|c|}{ Anaerobic Performance Parameters } \\
\hline & \multicolumn{2}{|c|}{ SJ } & \multicolumn{2}{|c|}{ CMJ } & \multicolumn{2}{|c|}{ WAnT AP } & \multicolumn{2}{|l|}{ WAnT AC } \\
\hline & $r$ & $\mathbf{p}$ & $r$ & $\mathbf{p}$ & $r$ & $\mathbf{p}$ & $r$ & $\mathbf{p}$ \\
\hline Body fat percentage & 0.114 & 0.674 & $-0.607^{*}$ & 0.013 & -0.326 & 0.217 & $-0.697^{* *}$ & 0.003 \\
\hline Body fat mass & 0.160 & 0.555 & $-0.579^{*}$ & 0.019 & -0.286 & 0.284 & $-0.719^{* *}$ & 0.002 \\
\hline Lean body mass & 0.018 & 0.948 & -0.165 & 0.543 & -0.108 & 0.692 & -0.423 & 0.103 \\
\hline Leg fat percentage & 0.176 & 0.515 & $-0.672^{* *}$ & 0.004 & -0.261 & 0.329 & $-0.634^{* *}$ & 0.008 \\
\hline Leg fat mass & 0.204 & 0.448 & $-0.539^{*}$ & 0.031 & -0.308 & 0.245 & $-0.658^{* *}$ & 0.006 \\
\hline Lean leg mass & 0.081 & 0.766 & -0.044 & 0.873 & -0.269 & 0.315 & -0.356 & 0.175 \\
\hline Torso fat percentage & 0.040 & 0.884 & $-0.530^{*}$ & 0.035 & -0.300 & 0.260 & $-0.702^{* *}$ & 0.002 \\
\hline Torso fat mass & 0.150 & 0.578 & $-0.607^{*}$ & 0.013 & -0.280 & 0.294 & $-0.747^{* *}$ & 0.001 \\
\hline Lean torso mass & 0.141 & 0.602 & -0.379 & 0.148 & -0.132 & 0.625 & -0.497 & 0.050 \\
\hline
\end{tabular}

Notes: ${ }^{*} \mathrm{p}<0.05 ;{ }^{*} \mathrm{p}<0.01 ; \mathrm{SJ}=$ Squat Jump; $\mathrm{CMJ}=$ Countermovement Jump; WAnT $\mathrm{AP}=$ Wingate Anaerobic Test Anaerobic Power; WAnT AC $=$ Wingate Anaerobic Test Anaerobic Capacity. 
power of the upper and lower extremities. Decreases in muscle power were associated with decreases in body fat observed in elite male handball players and considered disadvantageous for handball playing [11].

Anthropometric characteristics play a highly important role for the successful sportive performance in women handball players [12]. Vertical jumping ability is also an essential component in women handball, and it is frequently displayed in both defensive actions (e.g., blocking and stealing) and offensive movements (e.g., passing and shooting) [13]. However, the most studies to assess the relationships between anthropometric characteristics and performance parameters in team handball had focussed on throwing velocity $[3,11,14$, 15].

The present study showed that CMJ were negatively correlated with body fat percentages and body fat mass, leg fat percentages and leg fat mass, and torso fat percentages and torso fat mass. In addition, there were no significant correlations between SJ with total/ segmental body composition parameters. Contrary to the present study, Moss et al. [3] found that body mass was positively correlated to maximal and average power for $\mathrm{CMJ}$ ( $\mathrm{r}=0.77$ and $0.69 ; \mathrm{p}<0.05$, respectively) in female handball players. They also reported that higher skinfold values (body fat percentage) were found to negatively affect both maximal and average CMJ height $(\mathrm{r}=-0.56$ and $-0.57 ; \mathrm{p}<0.05$, respectively). The CMJ height were also negatively affected by higher body fat values that is showed the importance of team handball for the key performance determinant [3]. Similar to this study, Ciplak et al. [16] found that there was a positive relationship between fat free body mass and CMJ $(r=0.35 ; p<0.05)$ in Turkish female handball players. Unlike the current study, Saavedra et al. [17] didn't found a significant relationship between CMJ and body composition in female handball players. The current study' results showed that increase in total/segmental body fat percentage and body fat mass negatively affected to CMJ. Therefore, the decrease in fat mass may substantially improve elastic (reactive) power. Moss et al. [3] recommended that greater gluteal and calf girths were also beneficial for CMJ, suggesting that increased muscle mass in these areas contribute to movements involving a strength and power component.
The other physical parameters tested in this study were WAnT AC and WAnT AP. There were no significant relationships between WAnT AP and total/segmental body composition parameters but WAnT AC had negative significant relationships $(p<0.05)$ with body fat percentages, body fat mass, leg fat percentages, leg fat mass, torso fat percentages, and torso fat mass. These results showed that increase in total/segmental body fat percentage and fat mass negatively affected to WAnT AC. In literature, there were similar results in Perez-Gomez et al., [18] and Nkolaidis [19]. Nkolaidis [19] found that WAnT AC had negative correlations with body mass and body fat percentage $(\mathrm{r}=-0.40, \mathrm{r}=-0.42, \mathrm{p}<0.05$, respectively) in-season in female volleyball players. Perez-Gomez et al. [18] also reported that a significantly positive relationship between WAnT AC and lean leg mass in physical education students $(r=0.90, p<0.01)$. Contrary to the present study, Kucukkubas et al. [20] found that there was no relationship between body fat percent and WAnT (WAnT AP and WAnT AC) for female athletes (zumba, cross country runner, basketball, football, tennis, volleyball).

\section{Conclusion}

In conclusion, total/segmental body composition parameters based on endomorphy had negative effects on explosive power, elastic power, AP and AC. It is suggested that coaches should not allow female handball players to rise in ectomorphy for the physical performance loss in the season finale.

\section{Acknowledgements}

This study was supported by Anadolu University Scientific Research Projects (Project number: 1501S036). This study was presented as an oral presentation "Relationships of segmental and total body composition analysis with jumping, speed, agility, and anaerobic power-capacity parameters in-season in women handball players" in International Congress of Athletic Performance \& Health in Sports. Special thanks are also given to Women Handball Super League Team Players of Anadolu University Youth and Sports Club to participate in the study.

\section{Conflicts of Interest}

The authors declare no conflicts of interest. 


\section{References}

1. Lees MJ, Bansil K, Hind K. Total, regional and unilateral body composition of professional English first-class cricket fast bowlers, Journal of Sports Sciences, 2016;34(3):252-258. https://doi.org/10.1080/02640414.2015.1048274

2. Milanese C, Piscitelli C, Lampis C, Zancanaro C. Anthropometry and body composition of female handball players according to competitive level or the playing position. Journal of Sports Sciences, 2011;29(12):1301-1309. https://doi.org/10.1080/02640414.2011.591419

3. Moss SL, Mcwhannell N, Michalsik LB, Twist C. Anthropometric and physical performance characteristics of top-elite, elite and non-elite youth female team handball players. Journal of Sports Sciences, 2015;33(17):1780-1789. https://doi.org/10.1080/02640414.2015.1012099

4. Vila H, Manchado C, Rodriguez N, Abraldes JA, Alcaraz PE, Ferragut $\mathrm{C}$, Anthropometric profile, vertical jump, and throwing velocity in elite female handball players by playing positions. Journal of Strength \& Conditioning Research 2012;26(8):2146-2155. https://doi.org/10.1519/JSC.0b013e31823b0a46

5. Hoff M, Almasbakk B. The effects of maximum strength training on throwing velocity and muscle strength in female teamhandball players. Journal of Strength \& Conditioning Research 1995;9(4):255-258. https://doi.org/10.1519/00124278-199511000-00011

6. Saavedra JM, Kristjánsdóttir H, Einarsson I, Guðmundsdóttir M L, Porgeirsson S, Stefansson A. Anthropometric characteristics, physical fitness, and throwing velocity in elite women's handball teams, Journal of Strength \& Conditioning Research, 2017; 32(8):2294-2301. https://doi.org/ 10.1519/jsc.0000000000002412

7. Milanese C, Piscitelli F, Lampis C, Zancanaro C. Effect of a competitive season on anthropometry and threecompartment body composition in female handball players. Biology of Sport, 2012;29(3):199-204. https://doi.org/10.5604/20831862.1003443

8. Inbar O, Bar-Or O, Skinner JS. The Wingate anaerobic test. Champaign, IL: Human Kinetics; 1996.

9. Kale M, Aşçi A, Bayrak C, Açikada C. Relationships among jumping performances and sprint parameters during maximum speed phase in sprinters. Journal of Strength \& Conditioning Research, 2009;23(8):2272-2279. https://doi.org/10.1519/JSC.0b013e3181b3e182

10. Bosco C, Komi PV. Potentiation of the mechanical behaviour of the human skeletal muscle through prestretching. Acta Physiologica Scandinavica, 1979;106(4):467-472. https://doi.org/10.1111/j.1748-1716.1979.tb06427.x

11. Granados C, Izquierdo M, Ibanez J, Bonnabau H, Gorostiaga EM. Differences in physical fitness and throwing velocity among elite and amateur women's handball players. International Journal of Sports Medicine, 2007;28:860-867. https://doi.org/10.1055/s-2007-964989

12.Manchado C, Tortosa-Martinez J, Vila H, Ferragut C, Platen, P. Performance factors in women's team handball: Physical and physiological aspects-A review. Journal of Strength \& Conditioning Research, 2013;27(6):1708-1719. https://doi.org/10.1519/JSC.0b013e3182891535

13.Manchado C, Cortell-Tormo JM, Tortosa-Martínez J. Effects of two different training periodization models on physical and physiological aspects of elite female team handball players. Journal of Strength \& Conditioning Research, 2018;32(1):280-287. https://doi.org/10.1519/JSC.0000000000002259

14.Garcia M, Alcaraz PE, Ferragut C, Manchado C, Abraldes A, Rodriguez N, Vila H. Body composition and throwing velocity in elite women's handball. Ciencia Cultura Deporte, 2011;6(17):129-135. https://doi.org/10.12800/ccd.v6i17.40

15.Piscitelli F, Milanese C, Sandril M, Cavedon M, Zancanaro C. Investigating predictors of ball-throwing velocity in team handball: the role of sex, anthropometry, and body composition. Sport Sciences for Health, 2016;12(1):11-20. https://doi.org/10.1007/s11332-015-0248-7

16.Ciplak ME, Eler S, Joksimović, M, Eler N. The relationship between body composition and physical fitness performance in handball players. International Journal of Applied Exercise Physiology, 2019;8(3.1):347-353.

17. 17. Saavedra JM, Kristjánsdóttir $H$, Einarsson I, Guđmundsdóttir ML, porgeirsson S, Stefansson A. Anthropometric characteristics, physical fitness, and throwing velocity in elite women's handball teams. Journal of Strength \& Conditioning Research, 2018;32(8):2294-2301. https://doi.org/10.1519/JSC.0000000000002412

18.Perez-Gomez J, Rodriguez GV, Ara I, Olmedillas H, Chavarren J, Gonzalez-Henriquez JJ, Dorado C, Calbet J. Role of muscle mass on sprint performance: gender differences? European Journal of Applied Physiology, 2008;102(6):685-694. https://doi.org/10.1007/s00421-007-0648-8

19.Nikolaidis PT. Body mass index and body fat percentage are associated with decreased physical fitness in adolescent and adult female volleyball players, Journal of Research in Medical Sciences, 2013;18(1):22-26.

20.Kucukkubas N, Gunay A, Lokluoglu B, Kakil B. Relationship between body composition, vertical jump, 30m sprint, static strengthandanaerobic powerforathletes, InternationalJournal of Sport, Exercise \& Training Sciences, 2019;5(2):68-78. https://doi.org/10.18826/useeabd.517037 


\section{Information about the authors:}

Mehmet Kale; (Corresponding author); Dr., Assoc. Prof.; http://orcid.org/0000-0002-1960-2234; mkale@eskisehir.edu.tr; Department of Coaching Education, Faculty of Sport Sciences, Eskişehir Technical University; Eskişehir, Turkey.

Erkan Akdoğan; Dr., Assist. Prof.; http://orcid.org/0000-0002-8295-8524; eakdogan@eskisehir.edu.tr; Department of Coaching Education, Faculty of Sport Sciences, Eskişehir Technical University; Eskişehir, Turkey.

\section{Cite this article as:}

Kale M, Akdoğan E. Relationships between body composition and anaerobic performance parameters in female handball players. Physical Education of Students, 2020;24(5):265-270.

https://doi.org/10.15561/20755279.2020.0502

This is an Open Access article distributed under the terms of the Creative Commons Attribution License, which permits unrestricted use, distribution, and reproduction in any medium, provided the original work is properly cited http://creativecommons.org/licenses/by/4.0/deed.en

Received: 25.06 .2020

Accepted: 12.08.2020; Published: 30.10 .2020 